\title{
Influence of different response after neoadjuvant chemotherapy on time of surgery in breast cancer patients
}

\author{
Darko Zdravkovic ${ }^{1,2,3}$ (D) Simona Petricevic ${ }^{1} \cdot$ Borislav Toskovic $^{1,2}$ \\ Received: 17 February 2021 / Accepted: 20 February 2021 / Published online: 4 March 2021 \\ (c) The Author(s), under exclusive licence to Springer Science+Business Media, LLC part of Springer Nature 2021
}

We have read with great interest the article by Al-Masri et al. that evaluated effect of time to breast cancer surgery after neoadjuvant chemotherapy (NACT) on survival outcomes [1]. In this interesting article, the authors concluded that breast cancer surgery post-NACT within the first 8 weeks had no impact on survival outcome. Regarding this very important issue, we would like to highlight our point of view.

The optimal timing of systemic therapy in breast cancer patients has long been studied and debated. We would emphasize importance of correct assessment of the breast lesion during NACT. Clinical response should be evaluated clinically by palpation and radiologically by mammography and ultrasound or MRI-imaging. In particular, MRI-mammography is the standard of care for assessment of initial tumor size as well as treatment response [2]. According to the response evaluation criteria in solid tumors (RECIST) evaluation of target lesions implies complete response, partial response, stable disease and progressive disease [3]. We think that 8 weeks from the last dose of NACT to breast surgery is too long period for patients with progressive disease. In such cases, we suggest surgical treatment in less than 4 weeks.

Finally, according to our observations, methodology of this study must take into account all RECIST criteria to achieve more accurate results. Pathological complete response is the most important but not enough criteria in analysis of proper time of surgery after NACT in breast cancer patients.

Darko Zdravkovic

drdarkozdravkovic@gmail.com

1 University Medical Center "Bezaniska Kosa”, Belgrade, Serbia

2 Faculty of Medicine, University of Belgrade, Belgrade, Serbia

3 Department of Surgical Oncology, University Medical Center "Bezaniska Kosa", Belgrade, Serbia
Acknowledgements The authors have not received any grants.

\section{Declarations}

Conflict of interest The authors declare that they have no conflict of interest.

Ethical approval This article complies with the ethical rules applicable for this journal.

Human and animal rights This article does not contain any studies with human participants or animals performed by any of the authors.

\section{References}

1. Al-Masri M, Aljalabneh B, Al-Najjar H, Al-Shamaileh T (2021) Effect of time to breast cancer surgery after neoadjuvant chemotherapy on survival outcomes. Breast Cancer Res Treat. https:// doi.org/10.1007/s10549-020-06090-7

2. Fitzal F, Riedl O, Mittlböck M, Dubsky P, Bartsch R, Steger G, Jakesz R, Gnant M (2011) Oncologic safety of breast conserving surgery after tumour downsizing by neoadjuvant therapy: a retrospective single centre cohort study. Breast Cancer Res Treat 127(1):121-128

3. Therasse P, Arbuck SG, Eisenhauer EA, Wanders J, Kaplan RS, Rubinstein L, Verweij J, Van Glabbeke M, van Oosterom AT, Christian MC, Gwyther SG (2000) New guidelines to evaluate the response to treatment in solid tumors. European Organization for Research and Treatment of Cancer, National Cancer Institute of the United States, National Cancer Institute of Canada. J Natl Cancer Inst 92:205-216

Publisher's Note Springer Nature remains neutral with regard to jurisdictional claims in published maps and institutional affiliations. 